\title{
Comorbidity of Depression and Pain: A review of shared contributing mechanisms
}

\author{
Ai-Ling Li ${ }^{1-3^{*}}$, Yuan Bo Peng ${ }^{1}$ \\ 'Department of Psychology, The University of Texas at Arlington, 501 South Nedderman Drive, Arlington, Texas 76019, USA \\ ${ }^{2}$ Department of Psychological \& Brain Sciences, Indiana University Bloomington, 1101 E. 10th St., Bloomington, IN 47405, USA \\ ${ }^{3}$ Gill Center for Biomolecular Science, Indianan University Bloomington, 702 N. Walnut Grove Ave., Bloomington, IN 47405, USA
}

Article Info

\section{Article Notes}

Received: January 30, 2017

Accepted: February 27, 2017

${ }^{*}$ Correspondence:

Dr. Ailing Li, PhD

Address: 702 N. Walnut Grove Ave., Bloomington, IN 47405

USA.

Email: li555@iu.edu

() 2017 Ling Li A. This article is distributed under the terms of the Creative Commons Attribution 4.0 International License

\section{Keywords}

Pain

Depression

Comorbidity

Morphological changes

Monoamine

BDNF

HPA

\section{ABSTRACT}

Pain and depression are two major health issues that we are currently facing. Chronic pain is the main reason that people seek medical care; and numerous people commit suicide each year because of depression. These two pathological conditions often coexist. Chronic pain patients are more likely to develop major depressive symptoms, while depressed patients reported more pain symptoms than normal healthy population. Understanding the common mechanisms associated with depression and pain is important for developing the effective strategy to treat this comorbidity. In this review, the potential mechanisms that contribute to both depression and pain are discussed from four perspectives, the morphological changes in the brain, monoamine deficiency, brain-derived neurotrophic factor (BDNF) reduction in the hippocampus, and the hypothalamicpituitary-adrenocortical (HPA) axis dysfunction.

\section{Introduction}

Both chronic pain and major depression (MD) are important health issues. Pain is the leading reason that patients seek medical care. The annual cost pf pain (combining the health care cost and loss of productivity) in United States ranges from $\$ 560$ to 635 billion, which is greater than the annual costs of heart disease, cancer, and diabetes ${ }^{1,2}$. Depression now is the leading cause of disability worldwide and is estimated to affect 350 million people ${ }^{3}$. These two conditions often coexist. The prevalence of pain in patients with MD and the prevalence of depression in chronic pain patients are higher than the prevalence of pain or depression in general population ${ }^{4}$. Moreover, the condition of one can exacerbate the other. Chronic pain patients with depression are more likely to have higher severity and longer duration of pain, and the presence of pain is associated with increased depressive symptoms and possible relapses ${ }^{4-7}$. The detailed epidemiological information about the comorbidity of pain and depression was reviewed by Bair et al., (2003). It is important to treat pain and depression concurrently in comorbid populations. By targeting the common mechanisms shared by both pain and depression, we can better treat these comorbid conditions. This review discusses the potential mechanisms that contribute to both depression and pain from four perspectives, the morphological changes in the brain, monoamine, brain-derived neurotrophic factor (BDNF), and the hypothalamic-pituitary-adrenocortical (HPA) axis dysfunction. The animal models for pain and depression are also briefly reviewed. 


\section{Morphological changes in the brain}

\section{Morphological changes in depression}

Brain imaging studies and post-mortem studies showed that patients with depression had abnormal morphology in many brain structures ${ }^{8}$. Grey matter reduction is one of the major reasons. Left anterior cingulate cortex (ACC), which is ventral to the corpus collosum and is also called subgenual prefrontal cortex (SGPFC), showed prominent grey matter reduction in depressed patients 9 . Reduction of this area was found both in young women with early onset MD and middle aged women with recurrent $\mathrm{MD}^{10}$. The reduction in left posterior SGPFC is more prominent in MD patients compared with patients with other psychotic disorders, such as schizophrenia ${ }^{11}$. Decreased blood flow and activity in this area may contribute to the decrease in volume $^{12}$. Hippocampus also exhibited volume reduction in depressed patients ${ }^{13,14}$. Reduction in hippocampus was seen in patients with a history of early-life adversity ${ }^{15,16}$ and subjects with multiple depressive episodes ${ }^{17}$. Basal ganglia is another brain area showed grey matter reduction in depressed patients, more specifically the reduction was seen in putamen ${ }^{18,19}$ and caudate nuclei ${ }^{20,21}$. Besides grey matter reductions, white matter abnormalities have been observed in depressed patients ${ }^{22,23}$.

\section{Morphological changes in pain}

Chronic pain patients showed grey matter reduction in many brain areas. The most common areas that have grey matter decrease in chronic pain patients are the frontal cortex, ACC, insula, some areas in the temporal lobe ${ }^{24-30}$. Other areas, such as the thalamus, amygdala, motor cortex, and cerebellum, etc., also showed a decrease of grey matter depending on the type of chronic pain and disability the patients have ${ }^{31-33}$. The decreased grey matter was reversible in some cases after the pain was gone or was successfully treated ${ }^{28,30,34}$. Areas with increased grey matter were also noticed in some studies, such as the increased grey matter in the somatosensory cortex of migraine patients ${ }^{35}$, which is probably related to its crucial role of processing noxious and innocuous sensory information.

Structural changes of brain areas involved in both depression and pain appears to be consequences of these pathological conditions instead of causes, because these changes were reversible once the depression ${ }^{36}$ or chronic pain $^{28,30,34}$ has been treated. Overall, the brain areas that are mostly affected by both depression and pain are ACC, and the hippocampus in the temporal lobe. ACC is directly or indirectly connected to many other brain areas ${ }^{37}$, and is involved in the integration of emotion, cognition, autonomic function and conflict resolution ${ }^{38}$; these functions are disturbed during depression ${ }^{39}$. Additionally, ACC is highly involved in the affective component of pain ${ }^{40}$. The hippocampus in the temporal lobe is important in learning and memory, which are impaired in both depressed patients ${ }^{41}$ and some chronic pain patients ${ }^{42}$. Therefore, abnormality of ACC and hippocampus can contribute to the symptomology of both pain and depression.

\section{Monoamine}

\section{Monoamine and depression}

There are two major classes of antidepressants: the tricyclic antidepressants which block the plasma membrane transporter for serotonin (5-HT) and/or noradrenaline, and monoamine oxidase inhibitors which reduce the enzymatic breakdown of 5-HT and noradrenaline. Both categories increase the level of monoamine, which leads to the hypothesis that depression is caused by a deficiency of monoamines, such as noradrenaline, 5-HT, or both ${ }^{36,43}$. Therefore, based on this hypothesis, monoamine depletion was utilized to study the direct effects of monoamine on mood. However, conflicting results were found in heterogeneous populations. The monoamine depletions only had an effect in subjects with a family history of major depressive disorder (MDD) or in drug-free patients with MDD in remission, but did not decrease mood in healthy humans ${ }^{44}$. Additionally, it requires weeks of treatment with antidepressants to produce mood changes in clinical population, despite the relatively immediate increase of monoamine transmission after the administration of these drugs. Therefore, it was hypothesized that acute increase of monoamine induced by antidepressants produces secondary neuroplastic changes which takes longer time and alleviate depression ${ }^{43}$. In line with this hypothesis, studies have found antidepressants increased calpactin I light chain/annexin II (p11) which could increase serotonin $1 \mathrm{~B}$ receptor $\left(5-\mathrm{HT}_{1 \mathrm{~B}}\right)$ receptors at the cell surface ${ }^{45}$ and upregulate the transcription factor cAMP response element-binding protein (CREB) ${ }^{46}$.

\section{Monoamine and pain}

Monoamines play an important role in pain, especially in the descending inhibition of pain. The spinal cord is innervated by noradrenergic nuclei located in the brain stem $^{47}$. The noradrenergic projections to the dorsal horn modulate nociceptive signals before their transmissions to higher centers. Both stimulation of locus coeruleus ${ }^{48}$ and direct administration of noradrenaline to the spinal $\operatorname{cord}^{49,50}$ were antinociceptive. The release of noradrenaline acts predominantly on $\alpha_{2}$-adrenoceptor subclass and can inhibit transmitter release from primary afferent terminal and therefore suppress the activation of projection neurons in dorsal horn ${ }^{47}$. Serotonergic projections to the spinal cord mostly derives from rostral ventromedial medulla (RVM) and the dorsal raphe nucleus ${ }^{47}$. Both acute and chronic exposure to noxious stimuli can activate serotonergic 
neurons in the rostral ventromedial medulla (RVM) and facilitate the turnover of 5-HT in the spinal cord, therefore inhibit nociceptive transmission at the spinal $\operatorname{cord}^{51}$. 5- $\mathrm{HT}_{3}$ receptors has been discovered to mediate the inhibitory effect of 5-HT on dorsal horn neurons upon periaqueductal grey (PAG) stimulation ${ }^{52}$.

Overall, monoamines are highly implicated in both pain and depression. The brain stem nuclei send descending projections to spinal cord to modulate pain transmission and ascending projections to different brain areas to modulate mood, cognition and physiological function. The disruption of serotonergic and noradrenergic systems can contribute to the comorbidity of pain and depression.

\section{BDNF}

\section{BDNF and depression}

BDNF is the most prevalent growth factor in the central nervous system. It is known to be involved in survival and synaptic plasticity of central and peripheral nervous system. In human, the BDNF was significantly lower in depressed patients without antidepressant than those who were treated or control group ${ }^{53}$; and the BDNF was increased by antidepressant therapies ${ }^{54}$ and electroconvulsive therapy ${ }^{55}$. Similar phenomena were seen in animals ${ }^{46,56}$. Furthermore, direct administration of BDNF in the hippocampus can produce an antidepressant-like effect in animals. A single bilateral infusion of BDNF into the dentate gyrus of the hippocampus produced an antidepressant effect which lasted for at least 10 days in both learned helplessness and forced swim test (FST) paradigms ${ }^{57}$. This antidepressive effect of BDNF was comparable in magnitude with repeated systemic administration of chemical antidepressant ${ }^{57}$. BDNF was able to promote the function and growth of 5-HT containing neurons and increase the turnover of 5-HT and levels of noradrenaline in many forebrain areas ${ }^{58}$. Given the important role of 5-HT and noradrenaline in treating depression, the effect of BDNF on serotonergic neuron and serotonin suggested a potential link between BDNF and depression.

\section{BNDF and Pain}

Similar to depression, reduction of BDNF in the hippocampus was observed during pain ${ }^{59,60}$. But BDNF increased in spinal cord dorsal horn ${ }^{60,61}$ and periphery ${ }^{62,63}$ under pain conditions. Spinal administration of BDNF resulted in decreased nociceptive threshold ${ }^{64}$ and allodynia $^{61}$. The binding of BDNF to tropomyosin receptor kinase B (TrkB) receptor is possibly involved in the pronocicptive effect of BDNF, because the sequestration of BDNF by TrkB receptor chimera protein suppressed nerve injury-induced thermal hyperalgesia and tactile allodynia ${ }^{61,65}$. In addition, BDNF induced phosphorylation of $\mathrm{N}$-Methyl-D aspartic acid (NMDA) receptors on the spinal cord neurons, which is necessary for maintaining pain hypersensitivity after nerve injury ${ }^{66}$.

Although the BDNF changes differently at different location under pain condition, both pain and depression had reduction of BDNF in the hippocampus. It is interesting that the induction of BDNF by intracerebroventricular injection of 4-methycatechol (4-MC) reduced both the pain and depression response in rats caused by chronic constriction injury (CCI) of sciatic nerve, and this effect was blocked by anti-BDNF antibody ${ }^{67}$. This implies that the enhancement of BDNF in the brain may be a new treatment strategy for chronic pain associated with depression.

\section{Dysfunction of HPA axis in depression and pain}

The HPA axis is involved in the "flight or fight" response to stress. It consists of hypothalamus, pituitary and adrenal gland. External stressor activates hypothalamus to release corticotropin-releasing factor (CRF) which is delivered to and stimulate pituitary gland to release adrenocorticotropin hormone (ACTH). ACTH reaches adrenal gland through circulation and activate it to release glucocorticoids, such as cortisol which is involved in glucose metabolism ${ }^{68}$. Glucocorticoid, in turn, can suppress the production of CRH and ACTH to serve as the negative feedback mechanism for the HPA axis. Activation of the HPA axis is an adaptive process and enables organisms to respond to various challenges. However, continued and prolonged stress may disturb the HPA axis to such an extent that the negative feedback mechanism is disrupted; and the adaptive response of HPA axis then becomes maladaptive ${ }^{69}$.

\section{Depression and HPA axis}

Dexamethasone (DST) has been used to detect the HPA abnormalities in melancholic patients ${ }^{70-72}$. DST is an exogenous steroid that can suppress the ACTH release by binding to the glucocorticoid receptors (GR) in the anterior pituitary gland. Depressed patients did not show such inhibition of HPA axis by DST, and some patients showed hypersecretion of cortisol at baseline $\mathrm{e}^{70,72}$. Interestingly, not everyone who undergoes trauma develops abnormal HPA activity, only those who actually develop depression ${ }^{73}$.

This loss of inhibition of HPA axis or maladaptive of HPA negative feedback mechanism has been attributed to the glucocorticoid receptors (GRs) which play an important role in the negative feedback regulation of the HPA axis. Patients with bipolar or major depressive disorders, as well as first-degree relatives of those patients, displayed $\mathrm{GR} \alpha$ mRNA reduction ${ }^{74}$, which indicates the genetic involvement. Genetic manipulation of GR expression in mice made animals more prone to develop depressionlike behavior by under-expressing GR or more resistant to depression by over-expressing $\mathrm{GR}^{75}$. Antidepressants can also modify GR mRNA concentrations in primary 
culture of rat hypothalamic or cortical neurons ${ }^{76}$, elevate GR concentration in hypothalamus ${ }^{77}$, and reduce basal, as well as stress-induced plasma ACTH and corticosterone ${ }^{77}$. Therefore, antidepressant may alleviate depression through increasing the number of the corticosteroid receptors and restore susceptibility of HPA axis to negative feedback by cortisol $^{78}$. It is true that drugs specifically targeting HPA axis have shown promise in ameliorating depression symptoms ${ }^{69}$.

\section{Pain and HPA axis}

Unlike the depression for which the hypercortisolism is a common phenomenon, hypocortisolism is more common in chronic pain patients ${ }^{79-81}$. No escape from DST was observed in fibromyalgia (FMS) patients ${ }^{81}$. However, not all pain patients are associated with low cortisol level. Women with shoulder and neck pain had a tendency to develop higher elevated cortisol levels, and this hypercortisolism was suggested to represent an intermediate stage towards the development of a hypocortisolism in wide spread musculoskeletal pain ${ }^{80}$.

In summary, both pain patients and depressed patients showed maladaptive HPA function. However, depressed pain patients are more likely to develop hyperacitivity of HPA axis and result in hypercortisolism, while pain patients develop hypocortisolism.

\section{Animal models for depression and pain}

Animal models are great surrogates to study human disease in basic and preclinical research. They are pivotal for understanding the underlying pathophysiological mechanisms of disease and development of effective therapy. Therefore, the animal models of depression and pain are briefly summarized in this section to better understand how the animal models can be used to study the comorbidity of depression and pain (for more comprehensive and thorough reviews of depression models see ${ }^{82-84}$, and pain models see ${ }^{85-87}$ ).

Some depression models are used to screen for the efficacy of antidepressants. These tests are easy, low-cost, and highly reproducible; such as FST and tail suspension test (TST), in which animal is forced to swim in a confined space or is suspended by its tail respectively ${ }^{82-84}$. In these tests, animal becomes immobile after the initial struggle. The total immobility time is sensitive to anti-depressive treatment. Some other depression models incorporate stress as the major determinant. Learned helplessness introduces the uncontrollable and unpredictable stress, and results in the loss of motivation to escape in animals ${ }^{82-84,88}$. For example, a rat is placed in a chamber divided into two halves, with one of them is equipped with the floor which can deliver electric shock. Animal learns to escape to the safe side when hears a warning tone preceding the shock.
However, if the animal is confined to the side with shock and receives several unavoidable and uncontrolled shocks, animal will subsequently fail to escape when he is allowed to $^{84}$. In the chronic mild stress (CMS) model, animals are exposed to a series of mild and unpredictable stressors for at least 2 weeks, such as isolation or crowded housing, food or water deprivation, disruption of dark-light cycle, tilted home cages, dampened bedding, etc ${ }^{82-84}$. And sucrose intake is used as readout of anhedonia in this model. Additionally, social stress is adopted in depression models by introducing an intruder to the stable social group or mixing different social groups; and maternal separation is used as an early life stressor. Furthermore, there are depression models based on the putative pathophysiological mechanism, such as the deficiency of monoamine. Reserpine, a vesicular monoamine transporter blocker, has been used to deplete synaptic monoamines in depression models ${ }^{82-84}$. Others employ genetic manipulation to create mutant lines that display depressive symptoms ${ }^{82,83}$.

Animal pain models have been created in an attempt to recapitulate clinical conditions. To create inflammatory pain, irritant inflammatory agents are injected into different parts of the body, such as cutaneous and subcutaneous tissue, joint, and muscle, etc ${ }^{89}$. For example, formalin can be injected subcutaneously in the hind paw of rodents to induce biphasic pain responses. The initial phase lasts about 5 min after the injection, and then after quiescent period, a second phase persists for about 45 min. The spontaneous pain behaviors, such as flinching, shaking, or jerking of the injected paw, are quantified to indicate the present pain induced by formalin ${ }^{85,89}$. Other commonly used irritant algogenic agents are capsaicin, Freund's adjuvant, and carrageenan, etc. When these agents are injected intraperitoneally or directly into the hollow organs, such as colon, visceral pain is produced and writhing response can be measured ${ }^{85}$. Another major type of pain is the neuropathic pain which results from the injury or dysfunction of the nervous system. Many surgical variations have been invented to injure the nerve. For example, there are complete transection of the sciatic nerve, tight ligation of dorsal one third to half of the common sciatic nerve, tight ligation of L5 spinal nerve, tight ligation of peroneal and tibial nerve while leaving sural nerve intact, or spinal cord contusion, etc ${ }^{86,87}$. Inflammatory agent, such as zymosan, can also be applied to the nerve to induce neuropathic pain ${ }^{86}$. Additionally, chemotherapy-induced neuropathic pain is commonly seen in patients who receive chemotherapeutic drugs. Therefore, chemotherapeutic agents, such as vincristine, cisplatin and paclitaxel, have been repeatedly injected to animals to produce chemotherapy-induced peripheral neuropathy. Other disease-induced neuropathy models are diabetes- and cancer-induced neuropathy ${ }^{86}$. Many of the pain models can result in the peripheral hypersensitivity 
which can be measured by the reduced threshold to thermal or mechanical stimuli. To measure the hypersensitivity to mechanical stimuli, a pressure of increasing intensity is applied to the hind paw until the paw withdrawal. For example, a series of von Frey filaments of different diameters (producing different pressure when bent) are applied to the ventral or dorsal surface of the hind paw. The lowest pressure that produces withdrawal response is regarded as the mechanical threshold. Similarly, the thermal hypersensitivity can be measured by the reaction time of certain behavior when exposed to a thermal stimulus. An example of such test is the Hargreaves test in which a radiant heat is directed toward the plantar surface of the hind paw and the latency of paw withdrawal is recorded as the thermal threshold ${ }^{90}$. Sometimes, animal's response to cold is also measured. Vocalization is another parameter that is measured as the reaction to painful stimuli, and the stimulus intensity necessary to elicit a vocal response is determined ${ }^{85,89}$.

To study the comorbidity of depression and pain in animal models, it is necessary to evaluate the pain hypersensitivity in depression models and depressive proneness in pain models, and find the optimal model for the comorbidity of depression and pain. It can imagine that not every model will produce the same degree of comorbidity based on the differences in the etiologies and pathophysiological mechanisms for each model. Because the comorbidity was mostly seen in patients with chronic pain, it is more appropriate to incorporate chronic pain such as neuropathic pain, as opposed to the relatively transient pain such as formalin injection-induced pain. Furthermore, depression models with higher face validity involving stress as major determinant can better mimic clinical conditions as compared to the FST or TST.

\section{Summary}

As discussed above, there are common factors involved in both depression and pain: the grey matter decrease in ACC and hippocampus, deficiency in monoamine and reduction of BDNF in hippocampus. Although both depression and pain are associated with the malfunction of HPA axis, they differ in the direction of changes in HPA axis activity. Targeting at these shared mechanisms for pain and depression may increase the efficiency of treating patients with comorbidity of pain and depression. More research needs to be done in a comorbidity model to study the efficacy of targeting these factors in treating pain and depression. For example, does the increase of monoamine or BDNF level ameliorate both pain and depression? There is one study which has shown increased BDNF can increase pain threshold and alleviate depression in CCI model ${ }^{67}$, but more research needs to be done. Studies have shown that increased glucocorticoids and ACTH was able to increase monoamine oxidase activity to reduce monoamine level ${ }^{91,92}$. Decreased BDNF level could lead to changes of neuroplasticity and volume in critical brain areas ${ }^{46}$, such as the prefrontal cortex, ACC and hippocampus, which can result in the dis-regulation of mood and changed pain perception. Therefore, we also want to know how these mechanisms interact with each other and how they play as a whole in the comorbidity of depression and pain.

\section{References}

1. Gaskin DJ, Richard P. The Economic Costs of Pain in the United States. In: Relieving Pain in America. A Blue Print for Transforming Prevention, Care, Education, and Research. Washington, D.C.: The National Academies Press; 2011: 319-382. http://www.ncbi.nlm.nih. gov/books/NBK91497/pdf/TOC.pdf.

2. Gaskin DJ, Richard P. The economic costs of pain in the United States. J Pain. 2012; 13(8): 715-724. doi:10.1016/j.jpain.2012.03.009.

3. WHO. Depression, a global public health concern. WHO Department of Mental Health and Substance Abuse. http://www.who.int/ mental_health/management/depression/who_paper_depression_ wfmh_2012.pdf. Published 2012.

4. Bair MJ, Robinson RL, Katon W, et al. Depression and Pain Comorbidity. Arch Intern Med. 2003; 163(20): 2433-2445.

5. Lautenbacher S, Bär KJ, Eisold $\mathrm{P}$, et al. Understanding facial expressions of pain in patients with depression. J Pain. December 2016. doi:10.1016/j.jpain.2016.11.011.

6. Stubbs B, Koyanagi A, Thompson T, et al. The epidemiology of back pain and its relationship with depression psychosis anxiety sleep disturbances and stress sensitivity: Data from 43 low and middle income countries. Gen Hosp Psychiatry. 2016; 43: 63-70. doi:10.1016/j.genhosppsych.2016.09.008.

7. Tsuji T, Matsudaira K, Sato H, et al. The impact of depression among chronic low back pain patients in Japan. BMC Musculoskelet Disord. 2016; 17(1): 447. doi:10.1186/s12891-016-1304-4.

8. Koolschijn PCMP, van Haren NEM, Lensvelt-Mulders GJLM, et al. Brain volume abnormalities in major depressive disorder a meta analysis of magnetic resonance imaging studies. Hum Brain Mapp. 2009; 30(11): 3719-3735. http://www.ncbi.nlm.nih.gov/pubmed/19441021. Accessed August 17, 2012.

9. Drevets WC, Price JL, Furey ML. Brain structural and functional abnormalities in mood disorders implications for neurocircuitry models of depression. Brain Struct Funct. 2008; 213(1-2): 93-118. doi:10.1007/s00429-008-0189-x.

10. Botteron KN, Raichle ME, Drevets $\mathrm{WC}$, et al. Volumetric reduction in left subgenual prefrontal cortex in early onset depression. Biol Psychiatry. 2002; 51(4): 342-344. http://www.ncbi.nlm.nih.gov/ pubmed/11958786.

11. Coryell W, Nopoulos P, Drevets W, et al. Subgenual prefrontal cortex volumes in major depressive disorder and schizophrenia Diagnostic specificity and prognostic implications. 2005; 162: 1706-1712.

12. Drevets WC, Price JL, Simpson JR, et al. Subgenual prefrontal cortex abnormalities in mood disorders. Nature. 1997; 386(6627): 824-827. doi:10.1038/386824a0.

13. Videbech P, Ravnkilde B. Reviews and Overviews Hippocampal Volume and Depression A Meta Analysis of MRI Studies. Am J Psychiatry. 2004; 161: 1957-1966.

14. Mendl M, Burman OHP, Paul ES. An integrative and functional framework for the study of animal emotion and mood. Proc Biol Sci. 2010; 277(1696): 2895-2904. doi:10.1098/rspb.2010.0303.

15. Heim C, Ph D, Newport J, et al. Volume in Women With Major Depression. 2002; i(December): 2072-2080. 
16. Rao U, Chen LA, Bidesi AS, et al. Hippocampal changes associated with early life adversity and vulnerability to depression. Biol Psychiatry. 2010; 67(4): 357-364. doi:10.1016/j.biopsych.2009.10.017.

17. MacQueen GM, Campbell S, McEwen BS, et al. Course of illness hippocampal function and hippocampal volume in major depression. Proc Natl Acad Sci U S A. 2003; 100(3): 1387-1392. doi:10.1073/ pnas.0337481100.

18. Husain MM, McDonald WM, Doraiswamy PM, et al. A magnetic resonance imaging study of putamen nuclei in major depression. Psychiatry Res. 1991; 40(2): 95-99. http://www.ncbi.nlm.nih.gov/ pubmed/1763144. Accessed July 19, 2012.

19. Baumann B, Danos P, Krell D, et al. System Affiliated Basal Ganglia Data From a Postmortem Study. J Neuropsychiatry Clin Neurosci. 1999; 11(1): 71-78.

20. Krishnan KR, McDonald WM, Escalona PR, et al. Magnetic resonance imaging of the caudate nuclei in depression. Preliminary observations. Arch Gen Psychiatry. 1992; 49(7): 553-557. http://www.ncbi.nlm.nih. gov/pubmed/1627046. Accessed July 19, 2012.

21. Krishnan KR, McDonald WM, Doraiswamy PM, et al. Neuroanatomical substrates of depression in the elderly. Eur Arch Psychiatry Clin Neurosci. 1993; 243(1): 41-46. http://www.ncbi.nlm.nih.gov/ pubmed/8399409. Accessed July 19, 2012.

22. Guo W-B, Liu F, Xue ZM, et al. Altered white matter integrity in young adults with first episode treatment naive and treatment responsive depression. Neurosci Lett. 2012; 522(2): 139-144. doi:10.1016/j. neulet.2012.06.027.

23. Kieseppä T, Eerola M, Mäntylä R, et al. Major depressive disorder and white matter abnormalities a diffusion tensor imaging study with tract based spatial statistics. J Affect Disord. 2010; 120(1-3): 240-244. doi:10.1016/j.jad.2009.04.023.

24. Schmidt Wilcke T, Leinisch E, Straube A, et al. Gray matter decrease in patients with chronic tension type headache. Neurology. 2005; 65(9): 1483-1486. http://www.ncbi.nlm.nih.gov/pubmed/16275843. Accessed August 14, 2012.

25. Rocca M a, Ceccarelli A, Falini A, et al. Brain gray matter changes in migraine patients with T2-visible lesions: a 3-T MRI study. Stroke. 2006; 37(7):1765-1770.doi:10.1161/01.STR.0000226589.00599.4d.

26. Kim JH, Suh SI, Seol HY, et al. Regional grey matter changes in patients with migraine: a voxel-based morphometry study. Cephalalgia. 2008; 28(6): 598-604. http://cep.sagepub.com/content/28/6/598.full. Accessed August 17, 2012.

27. Absinta M, Rocca MA, Colombo B, et al. Selective decreased grey matter volume of the pain matrix network in cluster headache. Cephalalgia. 2012; 32(2): 109-115. http://cep.sagepub.com/content/32/2/109. full. Accessed August 17, 2012.

28. Obermann M, Nebel K, Schumann C, et al. Gray matter changes related to chronic posttraumatic headache. Neurology. 2009; 73(12): 978983. http://www.ncbi.nlm.nih.gov/pubmed/19770474. Accessed August 17, 2012.

29. Kuchinad A, Schweinhardt P, Seminowicz DA, et al. Accelerated brain gray matter loss in fibromyalgia patients: premature aging of the brain. J Neurosci. 2007; 27(15): 4004-4007. http://www.ncbi.nlm. nih.gov/pubmed/17428976. Accessed August 14, 2012.

30. Rodriguez Raecke R, Niemeier A, Ihle K, et al. Brain gray matter decrease in chronic pain is the consequence and not the cause of pain. J Neurosci. 2009; 29(44): 13746-13750. doi:10.1523/ JNEUROSCI.3687-09.2009.

31. Burgmer M, Gaubitz M, Konrad C, et al. Decreased gray matter volumes in the cingulo frontal cortex and the amygdala in patients with fibromyalgia. Psychosom Med. 2009; 71(5): 566-573. doi:10.1097/ PSY.0b013e3181a32da0.
32. Schmidt Wilcke T, Luerding R, Weigand T, et al. Striatal grey matter increase in patients suffering from fibromyalgia a voxel based morphometry study. Pain. 2007; 132 Suppl:S109-16. http://www. ncbi.nlm.nih.gov/pubmed/17587497. Accessed August 14, 2012.

33. Preißler S, Feiler J, Dietrich C, et al. Gray Matter Changes Following Limb Amputation with High and Low Intensities of Phantom Limb Pain. Cereb Cortex. April 2012. doi:10.1093/cercor/bhs063.

34. Seminowicz DA, Wideman TH, Naso L, et al. Effective treatment of chronic low back pain in humans reverses abnormal brain anatomy and function. J Neurosci. 2011; 31(20): 7540-7550. doi:10.1523/ JNEUROSCI.5280-10.2011.

35. DaSilva AFM, Granziera C, Snyder J, et al. Thickening in the somatosensory cortex of patients with migraine. Neurology. 2007; 69(21): 1990-1995. http://www.neurology.org/cgi/content/ abstract/69/21/1990. Accessed August 14, 2012.

36. Palazidou E. The neurobiology of depression. Br Med Bull. 2012; 101 127-145. doi:10.1093/bmb/lds004.

37. Zhuo M. Molecular mechanisms of pain in the anterior cingulate cortex. J Neurosci Res. 2006; 84(5): 927-933. http://www.ncbi.nlm. nih.gov/pubmed/16862566. Accessed August 18, 2012.

38. Bie B, Brown DL, Naguib M. Synaptic plasticity and pain aversion. Eur J Pharmacol. 2011; 667(1-3): 26-31. doi:10.1016/j.ejphar.2011.05.080

39. Alexopoulos GS, Gunning Dixon FM, Latoussakis V, et al. Anterior cingulate dysfunction in geriatric depression. Int $\mathrm{J}$ Geriatr Psychiatry. 2008; 23(4): 347-355. http://www.ncbi.nlm.nih.gov/ pubmed/17979214. Accessed August 18, 2012.

40. Rainville P, Duncan GH, Price DD, et al. Pain affect encoded in human anterior cingulate but not somatosensory cortex. Science. 1997; 277(5328): 968-971. http://www.ncbi.nlm.nih.gov/ pubmed/9252330. Accessed August 17, 2012.

41. BurtDB, Zembar MJ, Niederehe G. Depression and memory impairment A meta analysis of the association its pattern and specificity. Psychol Bull. 1995; 117(2): 285-305. doi:10.1037/0033-2909.117.2.285.

42. Hart RP, Wade JB, Martelli MF. Cognitive impairment in patients with chronic pain: The significance of stress. Curr Pain Headache Rep. 2003; 7(2): 116-126. doi:10.1007/s11916-003-0021-5.

43. Krishnan V, Nestler EJ. The molecular neurobiology of depression. Nature. 2008; 455(7215): 894-902. doi:10.1038/nature07455.

44. Ruhé HG, Mason NS, Schene AH. Mood is indirectly related to serotonin norepinephrine and dopamine levels in humans: a meta-analysis of monoamine depletion studies. Mol Psychiatry. 2007; 12(4): 331-359. doi:10.1038/sj.mp.4001949.

45. Svenningsson P, Chergui K, Rachleff I, et al. Alterations in 5-HT1B receptor function by 11 in depression like states. Science. 2006; 311(5757): 77-80. doi:10.1126/science.1117571.

46. Pittenger C, Duman RS. Stress depression and neuroplasticity: a convergence of mechanisms. Neuropsychopharmacology. 2008; 33(1): 88-109. doi:10.1038/sj.npp.1301574

47. Millan MJ. Descending control of pain. Prog Neurobiol. 2002; 66(6): 355-474. http://www.ncbi.nlm.nih.gov/pubmed/12034378.

48. Stamford JA. Descending control of pain. Br J Anaesth. 1995; 75: 217-227.

49. Shinomura $\mathrm{T}$, Nakao $\mathrm{S}$, Adachi $\mathrm{T}$, et al. Clonidine inhibits and phorbol acetate activates glutamate release from rat spinal synaptoneurosomes. Anesth Analg. 1999; 88(6): 1401-1405. http:// www.ncbi.nlm.nih.gov/pubmed/10357352. Accessed August 17, 2012.

50. Yaksh TL. Pharmacology of spinal adrenergic systems which modulate spinal nociceptive processing. Pharmacol Biochem Behav. 1985; 22(5): 845-858. http://www.ncbi.nlm.nih.gov/pubmed/2861606. Accessed August 17, 2012. 
51. Zhang YQ Gao X, Zhang LM, et al. The release of serotonin in rat spinal dorsal horn and periaqueductal gray following carrageenan inflammation. Neuroreport. 2000; 11(16): 3539-3543. http://www. ncbi.nlm.nih.gov/pubmed/11095514. Accessed August 17, 2012.

52. Peng YB, Lin $\mathrm{Q}$, Willis WD. The role of $5 \mathrm{HT} 3$ receptors in periaqueductal gray-induced inhibition of nociceptive dorsal horn neurons in rats. J Pharmacol Exp Ther. 1996; 276(1): 116-124. http://www.ncbi.nlm. nih.gov/pubmed/8558419. Accessed August 17, 2012.

53. Shimizu E, Hashimoto K, Okamura N, et al. Alterations of serum levels of brain derived neurotrophic factor (BDNF) in depressed patients with or without antidepressants. Biol Psychiatry. 2003; 54(1): 70-75. doi:10.1016/S0006-3223(03)00181-1.

54. Chen B, Dowlatshahi D, MacQueen GM, et al. Increased hippocampal BDNF immunoreactivity in subjects treated with antidepressant medication. Biol Psychiatry. 2001; 50(4): 260-265. http://www.ncbi. nlm.nih.gov/pubmed/11522260.

55. Piccinni A, Del Debbio A, Medda P, et al. Plasma Brain Derived Neurotrophic Factor in treatment resistant depressed patients receiving electroconvulsive therapy. Eur Neuropsychopharmacol. 2009; 19(5): 349-355. doi:10.1016/j.euroneuro.2009.01.002.

56. Nibuya M, Morinobu S, Duman RS. Regulation of BDNF and trkB mRNA in rat brain by chronic electroconvulsive seizure and antidepressant drug treatments. J Neurosci. 1995; 15(11): 7539-7547. http://www. ncbi.nlm.nih.gov/pubmed/7472505.

57. Shirayama Y, Chen ACH, Nakagawa S, et al. Brain derived neurotrophic factor produces antidepressant effects in behavioral models of depression. J Neurosci. 2002; 22(8): 3251-3261. doi:20026292.

58. Altar CA. Neurotrophins and depression. Trends Pharmacol Sci. 1999; 20(2): 59-61. http://www.ncbi.nlm.nih.gov/pubmed/10101965.

59. Duric V, McCarson KE. Hippocampal neurokinin-1 receptor and brain derived neurotrophic factor gene expression is decreased in rat models of pain and stress. Neuroscience. 2005; 133(4): 999-1006. http://www.ncbi.nlm.nih.gov/pubmed/15964488. Accessed August $17,2012$.

60. Duric V, McCarson KE. Neurokinin-1 (NK-1) receptor and brainderived neurotrophic factor (BDNF) gene expression is differentially modulated in the rat spinal dorsal horn and hippocampus during inflammatory pain. Mol Pain. 2007; 3: 32. http://archie.kumc.edu/ handle/2271/612. Accessed August 17, 2012.

61. Zhang X, Wang J, Zhou Q, et al. Brain derived neurotrophic factor activated astrocytes produce mechanical allodynia in neuropathic pain. Neuroscience. 2011; 199: 452-460. http://www.ncbi.nlm.nih. gov/pubmed/22044922. Accessed August 13, 2012.

62. Ha SO, Kim JK, Hong HS, et al. Expression of brain-derived neurotrophic factor in rat dorsal root ganglia spinal cord and gracile nuclei in experimental models of neuropathic pain. Neuroscience. 2001; 107(2): 301-309. http://www.ncbi.nlm.nih.gov/pubmed/11731104. Accessed August 13, 2012.

63. Cho HJ, Kim JK, Park HC, et al. Changes in brain-derived neurotrophic factor immunoreactivity in rat dorsal root ganglia spinal cord and gracile nuclei following cut or crush injuries. Exp Neurol. 1998; 154(1): 224-230. http://www.ncbi.nlm.nih.gov/pubmed/9875283. Accessed August 14, 2012.

64. Constandil L, Aguilera R, Goich M, et al. Involvement of spinal cord BDNF in the generation and maintenance of chronic neuropathic pain in rats. Brain Res Bull. 2011; 86(5-6): 454-459. http://www.ncbi.nlm. nih.gov/pubmed/21864655. Accessed August 13, 2012.

65. Yajima Y, Narita M, Usui A, et al. Direct evidence for the involvement of brain-derived neurotrophic factor in the development of a neuropathic pain like state in mice. J Neurochem. 2005; 93(3): 584594. doi:10.1111/j.1471-4159.2005.03045.x.
66. Wang LN, Yang JP, Ji FH, et al. Brain derived neurotrophic factor modulates $\mathrm{N}$-methyl-D-aspartate receptor activation in a rat model of cancer-induced bone pain. J Neurosci Res. 2012; 90(6): 1249-1260. http://www.ncbi.nlm.nih.gov/pubmed/22354476. Accessed August $13,2012$.

67. Fukuhara $\mathrm{K}$, Ishikawa $\mathrm{K}$, Yasuda $\mathrm{S}$, et al. Intracerebroventricular 4-Methylcatechol (4-MC) Ameliorates Chronic Pain Associated with Depression Like Behavior via Induction of Brain-Derived Neurotrophic Factor (BDNF). Cell Mol Neurobiol. 2012; 32(6): 971977. http://www.ncbi.nlm.nih.gov/pubmed/22198556. Accessed August 13, 2012.

68. Nestler EJ, Barrot M, Dileone RJ, et al. Neurobiology of Depression Review. 2002; 34: 13-25.

69. Blackburn Munro G, Blackburn Muron RE. Review Article Chronic Pain Chronic Stress and Depression : Coincidence or Consequence. J Neuroendocrinol. 2001; 13: 1009-1023.

70. Carroll BJ. The dexamethasone suppression test for melancholia. $\mathrm{Br}$ J Psychiatry. 1982; 140(3): 292-304. http://bjp.rcpsych.org/cgi/ content/abstract/140/3/292. Accessed July 20, 2012.

71. Lopez Duran NL, Kovacs M, George CJ. Hypothalamic pituitary adrenal axis dysregulation in depressed children and adolescents: a meta-analysis. Psychoneuroendocrinology. 2009; 34(9): 1272-1283. http://www.pubmedcentral.nih.gov/articlerender. fcgi $?$ artid $=2796553 \&$ to ol $=$ p mcentrez\&rendertype $=$ abstract . Accessed July 20, 2012.

72. Parker KJ, Schatzberg AF, Lyons DM. Neuroendocrine aspects of hypercortisolism in major depression. Horm Behav. 2003; 43(1): 6066. doi:10.1016/S0018-506X(02)00016-8.

73. Newport DJ, Heim C, Bonsall R, et al. Pituitary adrenal responses to standard and low dose dexamethasone suppression tests in adult survivors of child abuse. Biol Psychiatry. 2004; 55(1): 10-20. http:// www.ncbi.nlm.nih.gov/pubmed/14706420. Accessed July 20, 2012.

74. Matsubara T, Funato H, Kobayashi A, et al. Reduced Glucocorticoid Receptor alpha Expression in Mood Disorder Patients and First Degree Relatives. Biol Psychiatry. 2006; 59(8): 689-695. http://www. ncbi.nlm.nih.gov/pubmed/16458268. Accessed July 20, 2012.

75. Ridder S, Chourbaji S, Hellweg R, et al. Mice with genetically altered glucocorticoid receptor expression show altered sensitivity for stress-induced depressive reactions. J Neurosci. 2005; 25(26): 62436250. doi:10.1523/JNEUROSCI.0736-05.2005.

76. Pepin MC, Beaulieu S, Barden N. Antidepressants regulate glucocorticoid receptor messenger RNA concentrations in primary neuronal cultures. Brain Res Mol Brain Res. 1989; 6(1): 77-83. http:// www.ncbi.nlm.nih.gov/pubmed/2770454. Accessed August 2, 2012.

77. Reul JM, Stec I, Söder M, et al. Chronic treatment of rats with the antidepressant amitriptyline attenuates the activity of the hypothalamic-pituitary-adrenocortical system. Endocrinology. 1993; 133(1): 312-320. http://www.ncbi.nlm.nih.gov/pubmed/8391426. Accessed August 2, 2012.

78. Barden N, Reul JMHM, Holsboer F. Do antidepressants stabilize mood through actions on the hypothalamic-pituitary-. 1995; 18(1): 6-10.

79. Lentyes EGWM, Griep EN, Boersma JW, et al. Glucocorticoid receptors fibromyalgia and low back pain. Psychoneuroendocrinology. 1997; 22(8): 603-614.

80. Riva R, Mork PJ, Westgaard RH,et al. Comparison of the cortisol awakening response in women with shoulder and neck pain and women with fibromyalgia. Psychoneuroendocrinology. 2012; 37(2): 299-306. doi:10.1016/j.psyneuen.2011.06.014.

81. Griep EN, Boersma JW, de Kloet ER. Altered reactivity of the hypothalamic pituitary-adrenal axis in the primary fibromyalgia syndrome. J Rheumatol. 1993; 20(3): 469-474. http://www.ncbi.nlm. nih.gov/pubmed/8386766. Accessed August 16, 2012. 
82. Deussing JM. Animal models of depression. Drug Discov Today Dis Model. 2006; 3(4): 375-383. doi:10.1016/j.ddmod.2006.11.003.

83. McArthur R, Borsini F. Animal models of depression in drug discovery a historical perspective. Pharmacol Biochem Behav. 2006; 84(3): 436452. doi:10.1016/j.pbb.2006.06.005.

84. O'Neil MF, Moore NA. Animal models of depression: are there any Hum Psychopharmacol. 2003; 18(4): 239-254. doi:10.1002/hup.496.

85. Le Bars D, Gozariu M, Cadden SW. Animal models of nociception. Pharmacol Rev. 2001; 53(4): 597-652. http://www.ncbi.nlm.nih.gov/ pubmed/21341540.

86. Jaggi AS, Jain V, Singh N. Animal models of neuropathic pain. Fundam Clin Pharmacol. 2011; 25(1): 1-28. doi:10.1111/j.14728206.2009.00801.x.

87. Gregory NS, Harris AL, Robinson CR, et al. An overview of animal models of pain Disease models and outcome measures. J Pain. 2013; 14(11): 1255-1269.
88. Rupniak NMJ. Animal models of depression challenges from a drug development perspective. Behav Pharmacol. 2003; 14(5-6): 385-390. doi:10.1097/01.fbp.0000087738.21047.91.

89. Ren K, Dubner R. Inflammatory Models of Pain and Hyperalgesia. ILAR J. 1999; 40(3): 111-118. doi:10.1093/ilar.40.3.111.

90. Hargreaves K, Dubner R, Brown F, et al. A new and sensitive method for measuring thermal nociception. 1988; 32: 77-88.

91. Ou XM, Chen K, Shih JC. Glucocorticoid and androgen activation of monoamine oxidase $\mathrm{A}$ is regulated differently by $\mathrm{R} 1$ and $\mathrm{Sp} 1$. J Biol Chem. 2006; 281(30): 21512-21525. doi:10.1074/jbc.M600250200.

92. Kumamaru E, Numakawa T, Adachi N, et al. Glucocorticoid prevents brain derived neurotrophic factor-mediated maturation of synaptic function in developing hippocampal neurons through reduction in the activity of mitogen activated protein kinase. Mol Endocrinol. 2008; 22(3): 546-558. doi:10.1210/me.2007-0264. 